\title{
Benefits and harms of spinal manipulative therapy for the treatment of chronic low back pain: systematic review and meta-analysis of randomised controlled trials
}

\author{
Sidney M Rubinstein, ${ }^{1}$ Annemarie de Zoete, ${ }^{1}$ Marienke van Middelkoop, ${ }^{2}$ Willem J J Assendelft, ${ }^{3}$ \\ Michiel R de Boer, ${ }^{1}$ Maurits W van Tulder ${ }^{1,4}$
}

${ }^{1}$ Department of Health

Sciences, Faculty of Science,

Vrije Universiteit Amsterdam,

De Boelelaan 1085, 1081HV

Amsterdam, Netherlands

${ }^{2}$ Department of General

Practice, Erasmus Medical

Centre, Rotterdam, Netherlands

${ }^{3}$ Department of Primary and Community Care, Radboud

University Medical Centre,

Nijmegen, Netherlands

${ }^{4}$ Department of Physiotherapy

\& Occupational Therapy, Aarhus

University Hospital, Aarhus,

Denmark

Correspondence to:

SM Rubinstein

s.m.rubinstein@vu.n

(or@SM_Rubinstein)

(ORCID 0000-0002-4819-994X)

Additional material is published online only. To view please visit

the journal online.

Cite this as: $B M / 2019 ; 364: 1689$ http://dx.doi.org/10.1136/bmj.1689

Accepted: 07 February 2019

\section{ABSTRACT}

OBJECTIVE

To assess the benefits and harms of spinal manipulative therapy (SMT) for the treatment of chronic low back pain.

DESIGN

Systematic review and meta-analysis of randomised controlled trials.

\section{DATA SOURCES}

Medline, PubMed, Embase, Cochrane Central Register of Controlled Trials (CENTRAL), CINAHL, Physiotherapy Evidence Database (PEDro), Index to Chiropractic Literature, and trial registries up to 4 May 2018, including reference lists of eligible trials and related reviews.

\section{ELIGIBILITY CRITERIA FOR SELECTING STUDIES}

Randomised controlled trials examining the effect of spinal manipulation or mobilisation in adults ( $\geq 18$ years) with chronic low back pain with or without referred pain. Studies that exclusively examined sciatica were excluded, as was grey literature. No restrictions were applied to language or setting.

\section{REVIEW METHODS}

Two reviewers independently selected studies, extracted data, and assessed risk of bias and quality of the evidence. The effect of SMT was compared with recommended therapies, non-recommended therapies, sham (placebo) SMT, and SMT as an adjuvant therapy. Main outcomes were pain and back specific functional status, examined as mean differences and standardised mean differences (SMD), respectively. Outcomes were examined at 1 ,

\section{WHAT IS ALREADY KNOWN ON THIS TOPIC}

Numerous randomised controlled trials of varying methodological quality and size have examined the benefits and harms of spinal manipulative therapy (SMT) for the treatment of chronic low back pain

These trials have been summarised in numerous systematic reviews with varying results

SMT is not currently recommended as a first line treatment for chronic low back pain and its effects are uncertain

\section{WHAT THIS STUDY ADDS}

SMT has similar effects to recommended therapies for chronic low back pain, although it seems to be better for short term improvement in function

Data for the other comparisons (placebo SMT and SMT as adjuvant therapy) might be considered less robust and therefore unclear

Information is limited on the incidence of adverse events and serious adverse events with SMT for this population

6, and 12 months. Quality of evidence was assessed using GRADE. A random effects model was used and statistical heterogeneity explored.

\section{RESULTS}

47 randomised controlled trials including a total of 9211 participants were identified, who were on average middle aged (35-60 years). Most trials compared SMT with recommended therapies. Moderate quality evidence suggested that SMT has similar effects to other recommended therapies for short term pain relief (mean difference $-3.17,95 \%$ confidence interval -7.85 to 1.51 ) and a small, clinically better improvement in function (SMD $-0.25,95 \%$ confidence interval -0.41 to -0.09 ). High quality evidence suggested that compared with non-recommended therapies SMT results in small, not clinically better effects for short term pain relief (mean difference $-7.48,-11.50$ to -3.47 ) and small to moderate clinically better improvement in function (SMD $-0.41,-0.67$ to -0.15 ). In general, these results were similar for the intermediate and long term outcomes as were the effects of SMT as an adjuvant therapy. Evidence for sham SMT was low to very low quality; therefore these effects should be considered uncertain. Statistical heterogeneity could not be explained. About half of the studies examined adverse and serious adverse events, but in most of these it was unclear how and whether these events were registered systematically. Most of the observed adverse events were musculoskeletal related, transient in nature, and of mild to moderate severity. One study with a low risk of selection bias and powered to examine risk $(n=183)$ found no increased risk of an adverse event (relative risk 1.24 $95 \%$ confidence interval 0.85 to 1.81 ) or duration of the event $(1.13,0.59$ to 2.18$)$ compared with sham SMT. In one study, the Data Safety Monitoring Board judged one serious adverse event to be possibly related to SMT.

\section{CONCLUSION}

SMT produces similar effects to recommended therapies for chronic low back pain, whereas SMT seems to be better than non-recommended interventions for improvement in function in the short term. Clinicians should inform their patients of the potential risks of adverse events associated with SMT.

\section{Introduction}

Low back pain is a common and disabling disorder. ${ }^{1}$ Adequate treatment of low back pain is therefore important for patients, clinicians, and healthcare 
policy makers. Spinal manipulative therapy (SMT) is widely used to treat low back pain and has been examined in numerous randomised controlled trials of varying methodological quality and size, with varying results. These trials have been summarised in systematic reviews, including an earlier review of ours, and the results form the basis for recommendations in clinical guidelines. ${ }^{2-5}$

The effectiveness of SMT for the treatment of chronic low back pain and therefore recommendations in international guidelines for the use of non-drug interventions in the treatment of non-specific low back pain, are not without dispute. ${ }^{6}$ In some countries, SMT is considered a first line treatment option, ${ }^{3}$ whereas in others it is recommended as a component of a broader treatment package including exercise, ${ }^{5}$ or is not included or mentioned at all. ${ }^{4}$ The most recent summary of these guidelines suggests that SMT should be considered a second line or adjuvant treatment option, after exercise or cognitive behavioural therapy. ${ }^{7}$

In this review, we consider SMT to represent any hands-on treatment of the spine, including both mobilisation and manipulation. Mobilisations use low grade velocity, small or large amplitude passive movement techniques within the patient's range of motion and control, whereas manipulation uses a high velocity impulse or thrust applied to a synovial joint over a short amplitude at or near the end of the passive or physiological range of motion. ${ }^{8}$ This is often accompanied by an audible crack, resulting from cavitation of the joint.

\section{thebmi Visual Abstract $\bigcirc$ Spinal manipulative therapy Investigating published effectiveness for the treatment of chronic low back pain \\ Dif] Systematic review and meta-analysis} Observed effects were similar to those of recommended therapies, and appear to be better than non-recommended interventions for short term improvement in function

\section{Summary \\ Data sources}

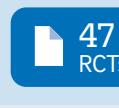

\&18 Comparison

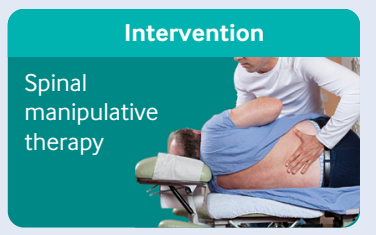

Most studies included people aged 35-60 years with or without radiating pain

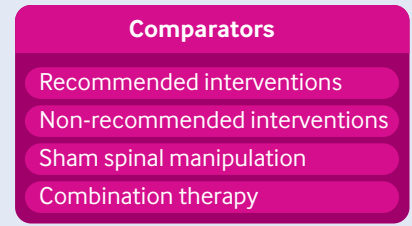

If Results

Spinal manipulative therapy versus recommended treatments

\section{Pain}

Low scores favour

intervention

\begin{tabular}{llll} 
At 1 month & 3155 & -15 & -10 \\
At 6 months & 2462 & & \\
\hline At 12 months & 2502 & & \\
At 1 month & 3090 & & -0.6
\end{tabular}

5 Evidence quality 5 (GRADE score)

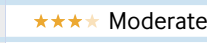
$* \star * *$ Moderate 0.2

Function Low scores favour intervention At 12 months
Many hypotheses about how SMT might work exist. ${ }^{9}{ }^{10}$ The modes of action can be roughly divided into biomechanical and neurophysiological. The mechanistic (biomechanical) approach suggests that SMT acts on a manipulable or functional spinal lesion; the treatment is designed to reduce internal mechanical stresses. ${ }^{11} 12$ The neurophysiological approach suggests that SMT affects the primary afferent neurons from paraspinal tissues, the motor control system, and pain processing. ${ }^{13-18}$

To resolve the issue of effectiveness, we conducted a systematic review and meta-analysis. This publication is an update of our earlier Cochrane review, which found high quality evidence suggesting no clinically relevant difference between SMT and effective interventions for reducing pain and improving function in patients with chronic low back pain. ${ }^{19}$ Data for the other comparisons were of lesser quality.

The primary objective of this current review was to examine the effectiveness of SMT on pain relief and improvement in function at the short, intermediate, and long term follow-up compared with control treatments for adults with chronic low back pain. Secondary objectives included the assessment of adverse events. The effect of SMT for other secondary outcomes, such as recovery, return to work, and health related quality of life are to be fully described elsewhere as an update of this review and published in the Cochrane Library.

\section{Methods}

This review follows the guidelines for Preferred Reporting Items for Systematic reviews and Metaanalyses (PRISMA). Our protocol is registered with the Cochrane Collaboration. ${ }^{20}$

\section{Criteria for considering studies for this review}

We only included published randomised studies. Studies using an inadequate randomisation procedure (eg, alternate allocation, allocation based on birth date) were excluded, as was grey literature.

Studies were considered eligible if they included adults ( $\geq 18$ years) and if more than $50 \%$ of the study population had pain lasting more than three months. Additionally, we included studies if the observed differences were thought to be due to the unique contribution of SMT, which may include studies in which SMT was delivered as part of a package of care-that is, if the effects of SMT could be isolated; for example, studies comparing SMT plus exercise with exercise alone would be included, whereas studies comparing SMT plus exercise with SMT alone would not. We excluded participants with postpartum low back pain or pelvic pain due to pregnancy, pain unrelated to the lower back, postoperative studies, patients with serious pathology, and studies that examined "maintenance care" or prevention; in addition to studies that were designed to test the immediate postintervention effect of a single treatment only as well as those studies that exclusively examined back related conditions (eg, sciatica). We also excluded studies if SMT was combined with other therapies, making it 
difficult to distinguish the effect of SMT-for example, a study comparing SMT plus exercise with another type of treatment (eg, general practitioner care).

This review focuses on the effects of both spinal manipulation (high velocity, low amplitude (HVLA) techniques) as well as mobilisation (low velocity, low amplitude (LVLA) techniques).

\section{Primary analyses}

We examined the effect of SMT compared with recommended therapies, non-recommended therapies, sham (placebo) SMT, and SMT as adjuvant therapy to any other therapy. Sham SMT was any comparator in which SMT involved hand contact, active or passive range of motion, or both, and techniques that simulated SMT but was designed not to deliver a therapeutic effect (eg, light touch or diminished therapeutic force), or even improper care (eg, improper patient positioning or purposely misdirected movements).

\section{Secondary analyses}

Although we considered the effect of HVLA SMT versus LVLA SMT (ie, manipulation versus mobilisation) as secondary because it was not included in our protocol, we included this comparison as it represents a point of continued discussion.

We based the determination of recommended and non-recommended interventions on recent international low back pain guidelines from the United States, ${ }^{3}$ United Kingdom, ${ }^{5}$ and Netherlands. ${ }^{4}$ An intervention was categorised into recommended or non-recommended when this was stated in two or more of these guidelines. The recommended control therapies examined in this review included non-drug (eg, exercise) and drug treatments (eg, non-steroidal anti-inflammatory drugs, analgesics), whereas nonrecommended interventions included non-effective (eg, light soft tissue massage, no treatment, waiting list control) or potentially even harmful treatments (eg, electrotherapies). When evidence conflicted, or the recommendation was not clear from these guidelines (eg, acupuncture), we consulted other guidelines, such as the COST B13 European guidelines. ${ }^{2}$

\section{Outcome measures}

The primary outcomes were pain intensity and back pain specific functional status. Adverse events and serious adverse events are summarised narratively.

\section{Search methods for identification of studies}

We identified randomised controlled trials from an electronic search of several databases (up to 4 May 2018): Cochrane Central Register of Controlled Trials (CENTRAL), Medline, Medline In-Process and Other Non-Indexed Citations, Embase, CINAHL, Physiotherapy Evidence Database (PEDro), Index to Chiropractic Literature, and PubMed. An experienced information specialist carried out the searches according to the recommendations of the Cochrane Handbook. ${ }^{21}$ In addition, we also screened the reference lists of all included studies and systematic reviews; searched trial registers, specifically, ClinicalTrials.gov and World Health Organization International Clinical Trials Registry Platform (ICTRP); and we sent our selection of studies to trial authors and specialists in SMT to identify any trials potentially missed. Appendix 1 shows the search terms and strategies.

\section{Data collection and analysis}

Two review authors (SMR, AdeZ) independently screened the titles and abstracts, evaluated the risk of bias, extracted data, and assessed the quality of the evidence (GRADE). Consensus was reached during meetings. Potentially relevant studies were obtained in full text and independently assessed for inclusion. Only full papers were evaluated. No language restrictions were applied.

Data extraction and management-A standardised form was used to extract the study design (randomised controlled trial), study and population characteristics, intervention and control characteristics, outcome measures, and follow-up intervals, as well other relevant data, such as source of funding, authors' declaration of interests, and risk of bias. Final value scores (means and standard deviations) were extracted for the meta-analyses. Change scores were converted into a mean value.

Assessment of risk of bias in included studiesrisk of bias was assessed according to the 13 criteria recommended by the Cochrane Back and Neck Review Group (see appendix 2). This tool is the same as that recommended by the Cochrane Collaboration, with the addition of items thought to be relevant in the assessment of non-drug trials, such as compliance, use of co-interventions, similarities of the groups at baseline, use of intention-to-treat analysis, and "other" (eg, potential conflicts of interest). We used this tool to evaluate selection bias, performance bias, detection bias, attrition bias, selective outcome reporting bias, and any other forms of bias, such as conflicts of interest. These criteria were scored as low risk, high risk, or unclear risk. Studies with fatal flaws were excluded from the meta-analyses, defined as studies with an exceedingly large drop-out rate or with statistically and clinically relevant important baseline differences, suggesting possibly improper randomisation or selective exclusion of data.

Measures of treatment effect-Pain is expressed as mean difference and functional status as a standardised mean difference (SMD), including 95\% confidence intervals. All pain scales were converted to a 100 point scale. A negative effect size indicates that SMT is more beneficial than the comparison therapy; meaning that participants have less pain or better functional status. A random effects model was used for all analyses based on the DerSimonian and Laird approach. ${ }^{22}$ Analyses were conducted in Review Manager 5.3.

Time and predication intervals-Outcomes were assessed at 1, 3, 6, and 12 months post-randomisation, and data were analysed according to the time closest to these intervals. The primary outcomes were defined 
as short term (one month), intermediate term (six months), and long term (12 months). We extracted the three month data for meta-analyses but these are not reported here. Additionally, we calculated prediction intervals for the outcomes. These intervals represent the expected range of true effects in similar studies and reflect the variation in treatment effects over different settings, including what effect is to be expected in a future trial. ${ }^{23}$

Assessment of clinical relevance-Clinical relevance was defined as small: mean difference $<10 \%$ of the scale (eg, $<10 \mathrm{~mm}$ on a $100 \mathrm{~mm}$ visual analogue scale) or SMD $\leq 0.5$; medium: mean difference $10-20 \%$ of the scale or SMD ranging from 0.5 to 0.8 ; large: mean difference $>20 \%$ of the scale or SMD $\geq 0.8$. The determination of clinical relevance originates from the behavioural sciences. ${ }^{24}$ These three levels are broadly used across systematic reviews and are recommended by the Cochrane Back and Neck Review Group, which included consumer/patient representatives. ${ }^{25}$

Unit of analysis issues-When multiple contrasts from the same trial were examined in the same comparison, we halved the number of participants in the shared comparison. This step accounts from problems arising when multiple arms from the same trial are examined in the same meta-analysis. "Halving" the number of participants corrects for error introduced by double counting. ${ }^{21}$

Dealing with missing data-When it was not possible to extract metadata from a publication, we used individual patient data if available. The research team has received these data from most studies published since 2000 for an individual patient data metaanalysis that we are currently conducting. In all other cases, we attempted to contact the author if data were missing. If no response was received, we followed the guidelines as outlined in the Cochrane Handbook (section 7.7.3). ${ }^{21}$

Assessment of reporting biases-Funnel plots were constructed, where possible, to explore publication bias. Additionally, we examined potential conflicts of interest as well as the funding source.

Data synthesis-GRADE was used to evaluate the overall quality of the evidence for each outcome, which ranges from high to very low quality and is based on five domains: limitations of design, inconsistency of results, indirectness, imprecision, and other factors, such as publication bias. Appendix 3 describes the criteria and operational definitions.

Assessment and investigation of heterogeneity-A prerequisite to pooling data was based on clinical homogeneity, which is why we stratified the metaanalyses by type of comparison, outcome, and time interval. Statistical heterogeneity was examined by inspecting the Forest plot and was formally tested using the $Q$ test $\left(\chi^{2}\right)$ and $\mathrm{I}^{2}$. We attempted to explain cases of considerable heterogeneity (defined as an $\mathrm{I}^{2}$ statistic $\geq 75 \%$ ) using meta-regression for those comparisons with sufficient data. The following variables were considered a priori: duration of the low back pain (subacute or chronic versus exclusively chronic), type of clinician (chiropractor versus other), type of radiating pain (above knee versus below knee); multimodal SMT (ie, SMT delivered alone compared with examined in a larger, multimodal context or as a package of care), and type of technique (HVLA versus LVLA). After examining the discriminative ability of these variables, we considered the additional variable of country where the study was conducted. Ultimately, we modelled just four variables: duration of the low back pain, type of clinician, multimodal SMT, and country. In the first step we conducted a univariate analysis and in a subsequent step we used the two variables showing the strongest effect to construct the final model. We report the effect and $\mathrm{I}^{2}$ for the final models only. These analyses were conducted in STATA, version 14.1.

Sensitivity analyses-Sensitivity analyses were planned a priori to determine the robustness of the data for risk of bias items (selection bias, performance bias, attrition bias, and selective outcome reporting bias), and by type of contrast (SMT versus exercise therapy). Among the risk of bias items we focused on selection bias, specifically treatment allocation, because this criterion showed exaggerated intervention effect estimates in a meta-analysis, which included a large collection of randomised trials published in the Cochrane Library. ${ }^{26}$

\section{Patient and public involvement}

No public or patient representatives were directly involved in the draft or process of this review. However, the primary outcomes examined in this review represent a core set recommended for low back pain, which included patient representatives in its development.

\section{Results}

In total, 47 trials fulfilled the inclusion criteria, 21 of which were not included in the previous review (fig 1). ${ }^{1427-72}$

\section{Included studies}

The countries in which the studies were conducted varied. Fifteen studies were conducted in the United States, ${ }^{14} 2829333440414445464954667072$ seven in the United Kingdom, 32353839506973 three each in Finland, ${ }^{425271}$ Australia, ${ }^{365167}$ and Italy, ${ }^{315565}$ two each in Sweden, ${ }^{5761}$ Denmark, ${ }^{5356}$ Egypt, ${ }^{5860}$ and India,,${ }^{59} 64$ and one each in Belgium, ${ }^{43}$ Spain, ${ }^{30}$ Switzerland, ${ }^{27}$ the Netherlands, ${ }^{47}$ Greece, ${ }^{48}$ Turkey, ${ }^{63}$ Pakistan, ${ }^{68}$ and Tunisia. ${ }^{37}$ All trials were published in English except the trial conducted in Tunisia, which was published in French. A detailed description of the characteristics of the included studies is available on request from the primary author. In total, 9211 patients were examined. Study sample sizes ranged from 21 to 1334 (median 132, interquartile range 64-240).

\section{Study population}

Most studies included middle aged participants (on average, 35-60 years of age) with or without 


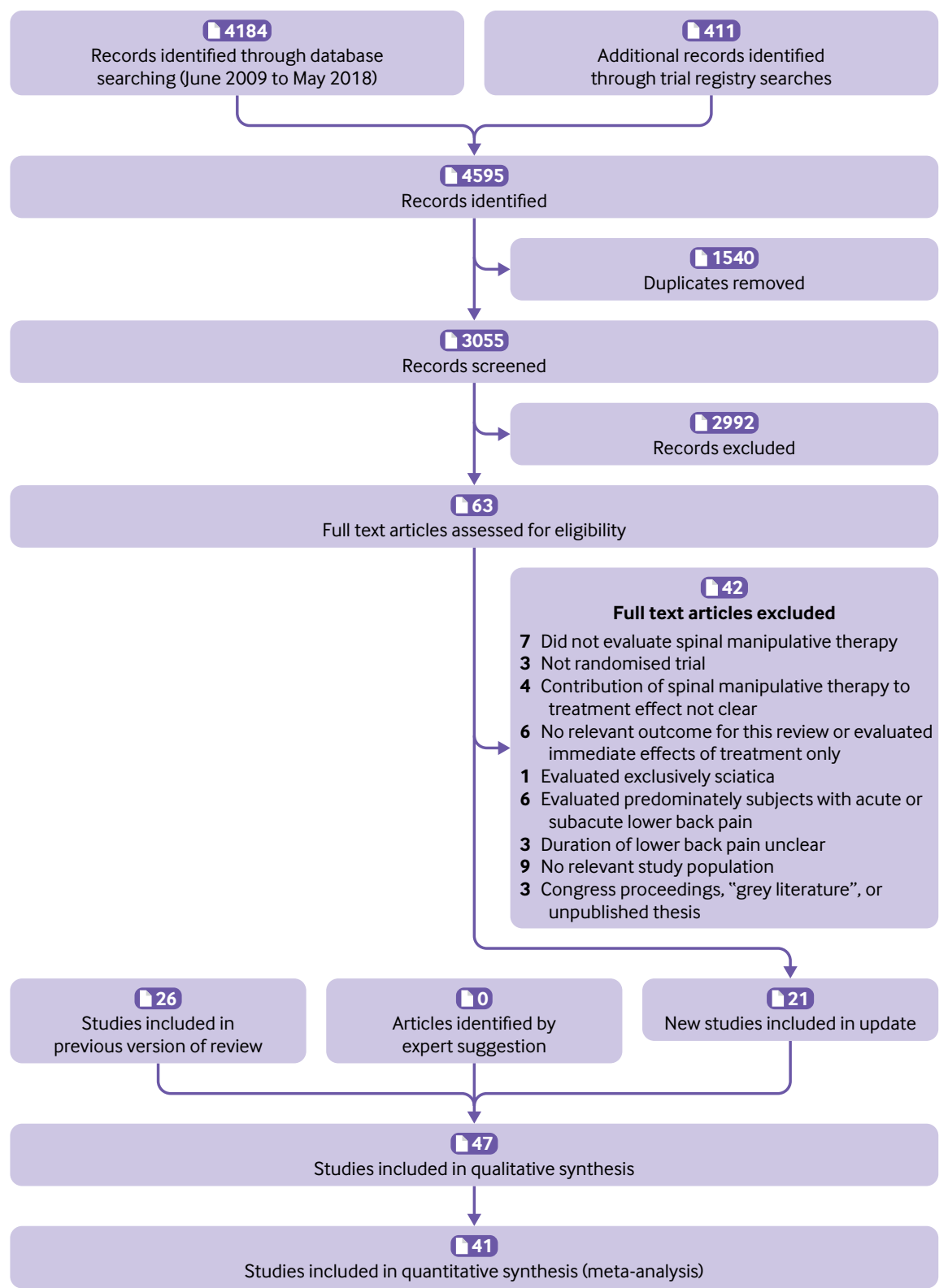

Fig 1 | Selection of studies through review

radiating pain. Less than half of the studies examined those with exclusively chronic low back pain $^{27} 3031323436394041484950515658596364656972$; however, among those studies that recruited a mixed population, the duration of the pain typically ranged from months to years (see table A in appendix 5). None of the studies made a clear distinction between persistent low back pain or exacerbation of a chronic condition.

\section{Provenance of evidence}

We would have liked to have described whether the research team was multidisciplinary and whether it included clinicians who were involved in the treatment, but in many cases these data were not reported. Importantly, no official disclosure was reported in most of the studies, although many were older studies for which disclosure was not standard procedure at the time.

\section{Primary investigators}

Affiliations-The primary investigators were affiliated with a department of physiotherapy or osteopathy within a university setting, ${ }^{1427} 3033364957585963646572$ health sciences department or similar within a university setting, ${ }^{29} 4143$ 46-48 51-54 61626771 department of medicine, rheumatology, or similar, 3537385055566068 chiropractic based research department, 28344044456670 or clinician initiated (independent of a university or college) 3132394269

Qualifications-The primary investigators (excluding potential training as a researcher, $\mathrm{PhD}$ ) were trained as chiropractor, ${ }^{28} 2934404144-46516769$ physical/manual therapist, ${ }^{14} \begin{array}{lllllllll}30 & 33 & 36 & 43 & 52 & 53 & 57 & 68\end{array}$ osteopath, ${ }^{49} 72$ medical doctor, ${ }^{31353738425055606271}$ or naturopathist, ${ }^{61}$ and some had no training as therapist or clinician 3947545970 or qualifications were unknown or unclear. ${ }^{273248565863646566}$ 
Involvement in treatment-In four studies the primary investigator was involved in treatment, ${ }^{14} 435268$ in nine not involved, ${ }^{27-3133-3638-42 ~ 44-47 ~ 495053-55 ~ 61-63 ~ 6667 ~ 70-73 ~}$ and in the remainder it was unknown or unclear. $3237485156-60646569$

\section{Funding and competing interests}

Fifteen of the studies were funded by government, ${ }^{27} 293032384142444750516263697012$ by a private or professional organisation, ${ }^{2831394953-57666771}$ and eight by a combination of these. ${ }^{1434364045466172}$
In 12 studies funding was not reported or was unclear. $^{33} 353743485258-60646568$

In 16 studies the authors declared no competing interests, $^{14} 27293031344143485360-62676870$ and in the remainder no official disclosure was reported $^{2832} 3335363739404244454647$ 49-52 54-59 63-66 69 717274

\section{Types of technique and practitioner}

Practitioners-In 16 studies treatment was delivered by a chiropractor, ${ }^{28293440414445465153-5566676970}$ in 14 by a manual or physical therapist, ${ }^{27} 303336394347485057-596364$

\begin{tabular}{|c|c|c|c|c|c|}
\hline Analyses & Effect estimate* $(95 \% \mathrm{Cl})$ & No of studies & No of participants & $I^{2}(\%)$ & $\begin{array}{l}\text { Quality of evidence } \\
\text { (reason for downgrading) }\end{array}$ \\
\hline \multicolumn{6}{|c|}{ Primary analyses } \\
\hline \multicolumn{6}{|c|}{ SMT versus recommended therapies } \\
\hline \multicolumn{6}{|l|}{ Pain: } \\
\hline 1 month & $-3.17(-7.85$ to 1.51$)$ & 17 & 3155 & 92 & Moderate (inconsistency) \\
\hline 6 months & $-3.09(-5.42$ to -0.77$)$ & 11 & 2462 & 58 & Moderate (inconsistency) \\
\hline 12 months & $-1.86(-4.79$ to 1.07$)$ & 10 & 2502 & 69 & Moderate (inconsistency) \\
\hline \multicolumn{6}{|c|}{ Functional status: } \\
\hline 1 month & $-0.25(-0.41$ to -0.09$)$ & 16 & 3090 & 76 & Moderate (inconsistency) \\
\hline 6 months & $-0.09(-0.21$ to 0.03$)$ & 12 & 2672 & 50 & Moderate (inconsistency) \\
\hline 12 months & $-0.09(-0.23$ to 0.04$)$ & 11 & 2635 & 62 & Moderate (inconsistency) \\
\hline \multicolumn{6}{|c|}{ SMT versus non-recommended therapies } \\
\hline \multicolumn{6}{|l|}{ Pain: } \\
\hline 1 month & $-7.48(-11.50$ to -3.47$)$ & 8 & 991 & 55 & High \\
\hline 6 months & $-7.54(-13.29$ to -1.79$)$ & 4 & 372 & 35 & Moderate (imprecision) \\
\hline 12 months & $-7.80(-14.19$ to -1.41$)$ & 1 & 169 & 0 & Low (inconsistency, imprecision) \\
\hline \multicolumn{6}{|c|}{ Functional status: } \\
\hline 1 month & $-0.41(-0.67$ to -0.15$)$ & 7 & 835 & 67 & High \\
\hline 6 months & $-0.29(-0.50$ to -0.09$)$ & 4 & 373 & 0 & Moderate (imprecision) \\
\hline 12 months & $-0.42(-0.72$ to -0.11$)$ & 1 & 169 & 100 & Low (inconsistency, imprecision) \\
\hline \multicolumn{6}{|c|}{ SMT versus sham SMT } \\
\hline \multicolumn{6}{|l|}{ Pain: } \\
\hline 1 month & $-7.55(-19.86$ to 4.76$)$ & 8 & 831 & 96 & Low (limitations, inconsistency) \\
\hline 6 months & $0.96(-6.34$ to 8.26$)$ & 2 & 114 & 35 & $\begin{array}{l}\text { Very low (limitations, inconsistency, } \\
\text { imprecision) }\end{array}$ \\
\hline 12 months & $0.20(-5.33$ to 5.73$)$ & 1 & 63 & 0 & $\begin{array}{l}\text { Very low (limitations, inconsistency, } \\
\text { imprecision) }\end{array}$ \\
\hline \multicolumn{6}{|c|}{ Functional status: } \\
\hline 1 month & $-0.73(-1.35$ to -0.11$)$ & 6 & 748 & 91 & Low (limitations, inconsistency) \\
\hline 6 months & $-0.12(-0.50$ to 0.25$)$ & 2 & 114 & 0 & $\begin{array}{l}\text { Very low (limitations, inconsistency, } \\
\text { imprecision) }\end{array}$ \\
\hline 12 months & $-0.19(-0.69$ to 0.31$)$ & 1 & 63 & 0 & $\begin{array}{l}\text { Very low (limitations, inconsistency, } \\
\text { imprecision) }\end{array}$ \\
\hline \multicolumn{6}{|c|}{ SMT as adjuvant therapy } \\
\hline \multicolumn{6}{|l|}{ Pain: } \\
\hline 1 month & $-6.93(-10.36$ to -3.49$)$ & 6 & 1046 & 41 & Moderate (limitations) \\
\hline 6 months & $-6.77(-14.07$ to 0.53$)$ & 2 & 143 & 0 & Low (limitations, imprecision) \\
\hline 12 months & $-3.31(-6.60$ to -0.02$)$ & 2 & 1000 & 12 & Moderate (limitations) \\
\hline \multicolumn{6}{|c|}{ Functional status: } \\
\hline 1 month & $-0.29(-0.55$ to -0.03$)$ & 4 & 955 & 62 & Moderate (limitations) \\
\hline 6 months & $-0.30(-0.64$ to 0.03$)$ & 2 & 142 & 0 & Low (imprecision, inconsistency) \\
\hline 12 months & $-0.21(-0.34$ to -0.09$)$ & 1 & 994 & 0 & Low (imprecision, inconsistency) \\
\hline \multicolumn{6}{|c|}{ Secondary analyses } \\
\hline \multicolumn{6}{|c|}{ HVLA SMT versus LVLA SMT } \\
\hline \multicolumn{6}{|l|}{ Pain: } \\
\hline 1 month & $0.32(-3.05$ to 3.69$)$ & 4 & 509 & 0 & Moderate (inconsistency) \\
\hline 6 months & No data available & - & - & - & - \\
\hline 12 months & No data available & - & - & - & - \\
\hline \multicolumn{6}{|c|}{ Functional status: } \\
\hline 1 month & $0.16(-0.42$ to 0.74$)$ & 4 & 520 & 90 & Low (inconsistency-two levels) \\
\hline 6 months & $0.16(-0.14$ to 0.46$)$ & 1 & 175 & 0 & Low (limitations, imprecision) \\
\hline 12 months & No data available & - & - & - & - \\
\hline
\end{tabular}


in six by a medical manipulator or orthomanual therapist, ${ }^{313552566068}$ in five by an osteopath, ${ }^{3238496572}$ in two by a bonesetter, ${ }^{42}{ }^{71}$ in one by a naprapath, ${ }^{61}$ and in one by several different disciplines. ${ }^{73}$ In another study, it was unclear what type of SMT treatment was delivered or the level or skill of the treating clinicians. ${ }^{37}$ In virtually all studies, experienced clinicians or therapists delivered the treatment, with the exception of one study where treatment was delivered by a few predoctoral osteopathic fellows. ${ }^{49}$

Techniques-Three types of primary technique were used in the SMT arm of the studies: high velocity, low amplitude (HVLA) thrust SMT, ${ }^{1428} 29333544455051$ 53-565960656670 low velocity, low amplitude (LVLA) passive movement techniques, $^{33} \quad 40 \quad 42 \quad 43 \quad 44 \quad 48 \quad 57 \quad 58 \quad 64 \quad 68 \quad 70 \quad 71$ or a combination (HVLA manipulation and LVLA mobilisation). ${ }^{27} 30313234363839414647495253616263656972$ In one study, the technique used was unclear, ${ }^{37}$ and in four studies, HVLA SMT was compared with LVLA SMT. $^{30334470}$

\section{Risk of bias in included studies}

Three studies were identified as having a major flaw and were excluded from the metaanalyses. $^{32} 3951$ Less than half of the studies (45\% $(n=21 / 47))$ used both an adequate sequence generation and an adequate allocation procedure. . $^{27} 3134364041424447536163676970717375$ Five studies $(10 \% \quad(n=5 / 47))$ attempted to blind patients to the assigned intervention by providing a sham treatment, ${ }^{3749606672}$ while in one study it was unclear. ${ }^{58}$ More than half of the studies $(57 \%(\mathrm{n}=27 / 47))$ provided an adequate overview of withdrawals or drop-outs and kept these to a minimum. ${ }^{1427293031 \text { 33-38 41-43 } 454748545961656769-7275}$ Less than one third of the studies $(30 \%(n=14 / 47))$ published or registered the protocol, and the reported outcomes were consistent with the protocol. ${ }^{1429} 3036414344485361-637172$ Appendix 4 summarises the risk of bias assessments.

\section{Effects of interventions}

Table 1 summarises the treatment effects and quality of the evidence for all comparisons.

\section{Primary analyses}

\section{SMT versus recommended interventions}

Twenty six studies compared the effects of SMT with recommended interventions. ${ }^{28} 2931323436394042444547$ 48 51-5355575961626368697175 Data could not be extracted from five studies, ${ }^{32} 39475155$ three of which had a major flaw.

Pain-Moderate quality evidence suggested that SMT is not statistically better than recommended interventions at one month and 12 months, although the difference was significant at six months. The size of the effect was, however, not clinically relevant (fig 2). Exclusion of extreme outliers accounted for a large percentage of the statistical heterogeneity for this outcome at one month (mean difference -0.39, 95\% confidence interval -2.41 to 1.62; participants=3005; studies $=23 ; \mathrm{I}^{2}=44 \%$ ), while the overall effect remained virtually unchanged.

Back specific functional status-Moderate quality evidence suggested that SMT results in a small, statistically better effect than recommended interventions at one month but not statistically better effect at six and 12 months (fig 3). Exclusion of extreme outliers accounted for a large percentage of the statistical heterogeneity for this outcome at one month (SMD -0.12, 95\% confidence interval -0.23 to -0.01 ; participants=2907; studies=22; $I^{2}=44 \%$ ), while the overall effect remained virtually unchanged.

\section{SMT versus non-recommended interventions}

Eleven studies compared the effects of SMT with nonrecommended interventions. 1427384145475054556770 Data could not be extracted from three studies. ${ }^{475455}$

Pain-High quality evidence suggested that SMT results in a small, statistically significant but not clinically better effect than non-recommended interventions at one month. Moderate quality evidence suggested that SMT results in a statistically significant but not clinically better effect at six months, and low quality evidence that SMT results in a statistically significant but not clinically better effect at 12 months (fig A in appendix 5).

Back specific functional status-High quality evidence suggested that SMT results in a small to moderate statistically and clinically better effect than nonrecommended interventions at one month. Moderate quality evidence suggested that SMT results in a small, statistically significant and clinically better effect at six months, and low quality evidence that SMT results in a small to moderate, statistically significant and clinically better effect at 12 months (fig B in appendix 5).

\section{SMT versus sham SMT}

Seven studies compared the effect of SMT with sham SMT. ${ }^{14374349606672}$

Pain-Low quality evidence suggested that SMT does not result in a statistically better effect than sham SMT at one month. Exclusion of an extreme outlier accounted for a large percentage of the statistical heterogeneity for this outcome at this time interval (mean difference -3.49 , 95\% confidence interval -6.03 to -0.94 ; participants $=781$; studies $=9 ; I^{2}=5 \%$ ), while the overall effect remained virtually unchanged. Additionally, very low quality evidence suggested that SMT does not result in a statistically better effect than sham SMT at six and 12 months (fig $C$ in appendix 5).

Back specific functional status-Low quality evidence suggested that SMT results in a moderate to strong statistically significant and clinically better effect than sham SMT at one month. Exclusion of an extreme outlier accounted for a large percentage of the statistical heterogeneity for this outcome at this time interval (SMD $-0.27,95 \%$ confidence interval -0.52 to -0.02 ; participants $=698$; studies $=7 ; \mathrm{I}^{2}=39 \%$ ), resulting in a small, clinically better effect in favour of SMT. Additionally, very low quality evidence suggested that SMT does not result in a statistically significant 


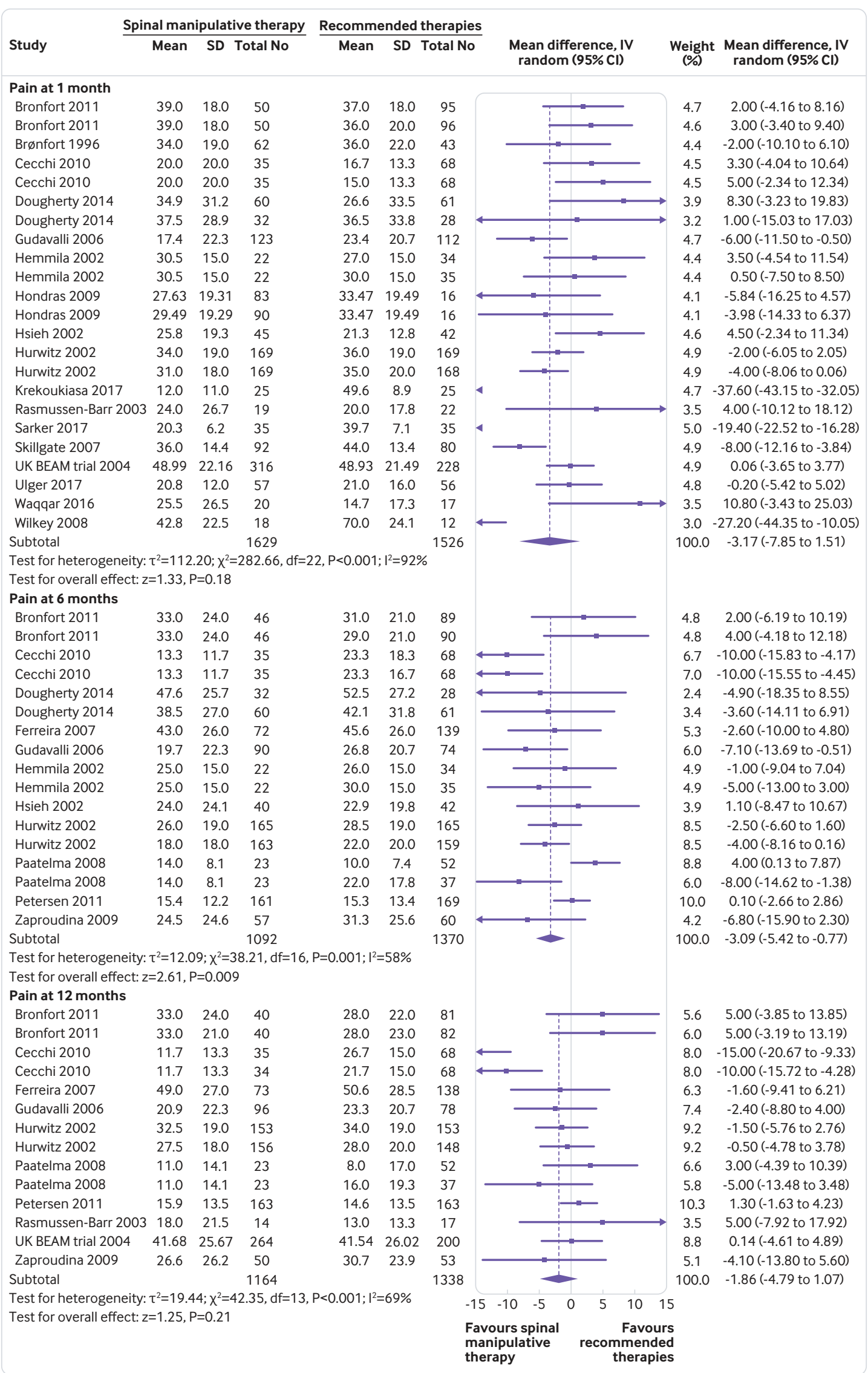

Fig 2 Mean difference in reduction of pain at 1, 3,6, and 12 months $(0-100 ; 0=$ no pain, 100 maximum pain) for spinal manipulative therapy (SMT) versus recommended therapies in review of the effects of SMT for chronic low back pain. Pooled mean differences calculated by DerSimonian-Laird random effects model. See supplementary file for more detailed graphic 


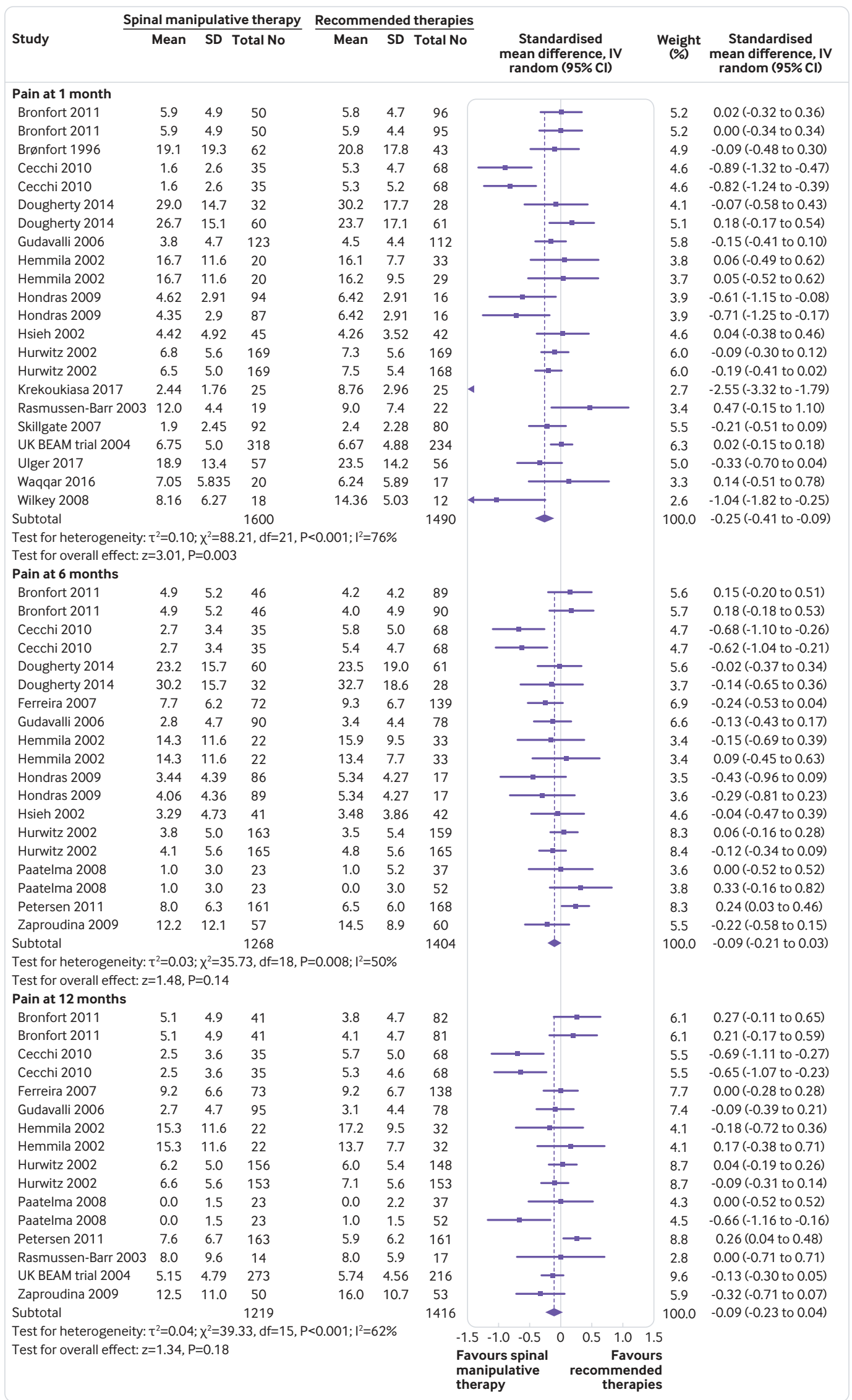

Fig 3 | Standardised mean difference for improvement in function at 1, 3, 6, and 12 months for spinal manipulative therapy (SMT) versus recommended therapies in review of the effects of SMT for chronic low back pain. Pooled standardised mean differences calculated by DerSimonianLaird random effects model. See supplementary file for more detailed graphic 
better effect than sham SMT at six and 12 months (fig $\mathrm{D}$ in appendix 5).

\section{SMT as adjuvant therapy}

Seven studies examined the adjuvant effects of SMT when combined with other therapies. ${ }^{354549} 56646573$

Pain-Moderate quality evidence suggested that SMT results in a small, statistically significant but not clinically better effect at one month and 12 months, and low quality evidence that SMT does not result in a statistically better effect as an adjuvant therapy at six months (fig E in appendix 5).

Back specific functional status-Moderate quality evidence suggested that SMT results in a small, statistically significant and clinically better effect at one month, and low quality evidence that SMT results in a small, statistically significant and clinically better effect at 12 months, but not statistically significant effect at six months (fig F in appendix 5).

\section{Secondary analyses}

HVLA SMT versus LVLA SMT-Four studies examined the effect of HVLA SMT versus LVLA SMT. ${ }^{30} 334470$ We found no statistically significant difference in effect between either technique for pain relief or improvement in function at one month (judged to be moderate and low quality, respectively). The evidence at six months was of low quality and there were no data for 12 months.

Mobilisation versus mobilisation-One small study with a high risk of bias for many criteria compared the effects of Maitland mobilisation with Mulligan mobilisation. ${ }^{58}$ The authors concluded that there was no significant difference between either technique for the short term reduction of pain.

Prediction intervals-Prediction intervals for the effect of SMT versus recommended therapies suggested a small to moderate effect in favour of either therapy, meaning that the therapy chosen by patients and clinicians should be based on factors other than effectiveness alone. Data were too few for the other comparisons to ascribe a meaningful interpretation to those results (table B in appendix 5).

\section{Explanation of statistical heterogeneity and sensitivity analyses}

We conducted meta-regression only for the comparison of SMT with recommended therapies. In general, two variables were typically included in the final model: multimodal SMT and duration of the low back pain (tables C and D in appendix 5). However, these variables did not explain the statistical heterogeneity for short term outcomes, and marginally for intermediate and long term outcomes. The moderator effects were also typically small and not clinically relevant. This meant that there was appreciably no difference in effect when SMT was offered as a package of care (as opposed to SMT alone) or when patients with exclusively chronic low back pain were included (as opposed to a mixed population). Meta-regression was not conducted for the other comparisons because data were too few to ascribe any meaningful interpretation to those results.
Additionally, no appreciable difference was found in effects for risk of bias or when the effect of SMT versus exercise was examined.

Publication bias-Publication bias was only examined for SMT versus recommended therapies, owing to the paucity of data for the other comparisons. We constructed two separate funnels plots for pain and functional status for all time measurements (figs $\mathrm{G}$ and $\mathrm{H}$ in appendix 5). Although these funnel plots do not suggest publication bias, this cannot be ruled out.

\section{Adverse events}

About half of the studies examined adverse events

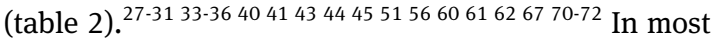
of these studies it was unclear how and whether adverse events were registered systematically 29303334616267 ; therefore, these data might be unreliable and not accurate for incidence. However, one of the studies included in this review ${ }^{67}$ was a secondary analysis of a trial designed to examine the incidence of these events. ${ }^{76}$ That study $(n=183)$ suggested no increased risk of an adverse event (relative risk 1.24, $95 \%$ confidence interval 0.85 to 1.81 ) or severe adverse event $\left(1.9,0.98\right.$ to 3.99 ) compared with sham SMT. ${ }^{76}$ Two studies reported serious adverse events ${ }^{34}$ : in one the Data Safety Monitoring Board judged none of these events to be associated with SMT, ${ }^{34}$ and in the other the Data Safety Monitoring Board judged one event to be possibly related to SMT. ${ }^{72}$

\section{Discussion}

In the treatment of chronic low back pain in adults, moderate quality evidence suggests that spinal manipulative therapy (SMT) results in similar outcomes to recommended therapies for short, intermediate, and long term pain relief as well as improvement in function. In addition, the quality of evidence varied suggesting that SMT does not result in clinically better effects for pain relief but does result in clinically better short term improvement in function compared with non-recommended therapies, or sham, and when included as an adjuvant therapy.

Most studies examined the effect of SMT in a pragmatic setting and might therefore be considered the most robust evidence. Given the considerable data available, we can now calculate within reasonable certainty the effect of SMT in this setting as well as the impact of a future, methodologically well conducted trial (as determined by the prediction intervals). Evidence for the remaining comparators was considered to be of moderate quality or lower (with the exception of the short term effect of SMT versus non-recommended therapies), suggesting some uncertainty around these effect estimates. However, it is questionable whether additional studies are necessary, and it is debatable whether studies that examine the effect of SMT compared with non-recommended therapies or sham (placebo) therapies will add further to our understanding. In fact, during this update we identified several, recent small pragmatic studies with a high risk of bias. ${ }^{4858596368}$ This is of concern 


\section{Table 2 | Summary of adverse event assessments among trials included in systematic review of spinal manipulative therapy (SMT) for chronic low back} pain

\section{Methods used}

\section{to assess}

Study, sample size adverse events

Balthazard 2012, $\mathrm{n}=42$ Not reported
Adverse events assessed Self reported throughout Any adverse event follow-up

\section{Adverse events reported (for SMT or control group)}

No adverse events reported; but one patient dropped out in each group owing to severe pain "All adverse events were transient in nature, required little or no change to activity levels, and were considered non-serious," 6 (2\%) patients were treated with rescue pain medication during treatment period: severe back pain, acute flare-up of low back and buttock pain, neck pain, and inability to sleep because of pain. Four (1\%) patients reported similar adverse events but declined rescue medication

Non-steroidal anti-inflammatory drug group: 2 (4\%) patients developed severe nausea and vomiting and subsequently discontinued the study, 8 (16\%) developed substantial nausea and dyspepsia, and 1 (2\%) developed severe tinnitus; SMT+exercise groups: 1 (2\%) patient discontinued exercise because she did not tolerate it well and 7 (14\%) developed muscle soreness and stiffness, including neck pain after exercise-these symptoms gradually abated and did not prevent completion of the study; 1 (1\%) developed symptoms of a myocardial infarction unrelated to exercise. "Overall, both strengthening and stretching exercise and SMT were well tolerated"

\begin{tabular}{llll}
$\begin{array}{l}\text { Castro-Sanchez 2016, } \\
\mathrm{n}=62\end{array}$ & $\begin{array}{l}\text { Self reported after treat- } \\
\text { ment and follow-up }\end{array}$ & Any adverse event & No adverse events reported \\
\hline Cecchi 2010, $\mathrm{n}=210$ & Not reported & Any adverse event & No adverse events reported \\
\hline Cook 2013, $n=154$ & Physiotherapists queried & Any adverse event & No adverse events reported
\end{tabular}
adverse events reported

Dougherty $2014 a$ at end of study

$n=181$

243 adverse events were reported during the study: 55\% in exercise group and 45\% in SMT group. Of 110 events reported in the SMT group, the Data Safety Monitoring Board (DSMB) judged 14 as definitely or probably associated with SMT. Most adverse events consisted of musculoskeletal soreness and resolved within study period. During the study period, 10 serious adverse events were reported ( 5 control group, 5 SMT group); DSMB judged none of the serious adverse events to be associated with the study intervention

\begin{tabular}{lll}
\hline Evans 1978, $\mathrm{n}=36$ & Not reported & Any adverse event \\
\hline Ferreira 2007, $\mathrm{n}=240$ & Not reported & Any adverse event \\
\hline Gudavalli 2006, $\mathrm{n}=235$ & Not reported & Any adverse event \\
\hline Haas 2014, $\mathrm{n}=400$ & Not reported & Any adverse event
\end{tabular}

(3\%) patient reported constipation after consumption of 24 codeine phosphate capsules in first 4 days; no serious adverse events reported

No adverse events reported, one patient died, and one was admitted to hospital, in control group

No adverse events reported

$3(1 \%)$ patients reported seeking care for symptomatic relief of low back pain exacerbation related to study, 1 (1\%) lost several days of work followed by complete resolution during treatment phase, and 1 (1\%) dropped out after an exacerbation associated with lifting a child no serious adverse events reported

\begin{tabular}{lll} 
Hidalgo 2015, $n=32$ & Not reported & Any adverse event \\
\hline Hondras 2009, $n=240$ & Not reported & Any adverse event
\end{tabular}
No serious or moderate adverse events reported

Hondras $2009, n=240$ Not reported

$20(8 \%)$ patients reported an adverse event, all resolved within 6 days, and none required referral for outside care. Adverse events in SMT groups consisted of soreness or stiffness. 1 patient reported a skin rash in drug group; no serious adverse events reported

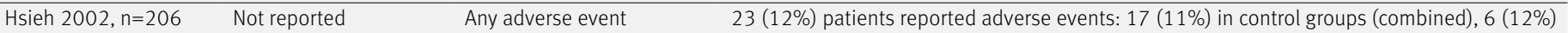
in SMT group; adverse events were limited to transient exacerbations of symptoms, except for one case of constant tinnitus in a control group; 2 (4\%) patients claimed SMT had aggravated their condition; no serious adverse events reported

Licciardone 2013, Not reported Any adverse event $n=455$

27 (6\%) patients reported an adverse event; 9 (2\%) reported a serious adverse event ("none was definitely or probably related to a study intervention" according to DSMB); no significant differences between groups in frequency of (serious) adverse events; 6 patients who received SMT developed a contraindication to continued study participation (SMT was adjudicated by DSMB to be possibly related to development in only one of these)

\begin{tabular}{|c|c|c|c|}
\hline Muller $2005, n=115$ & Not reported & Any adverse event & $\begin{array}{l}3(6 \%) \text { patients in drug group experienced an adverse event; no serious adverse events } \\
\text { reported }\end{array}$ \\
\hline $\begin{array}{l}\text { Rasmussen 2008, } \\
\mathrm{n}=72\end{array}$ & Not reported & Any adverse event & $\begin{array}{l}4(11 \%) \text { patients in SMT group reported worsening of low back pain versus } 3(8 \%) \text { in control } \\
\text { group; no serious adverse events reported }\end{array}$ \\
\hline Senna 2011, n=93 & Not reported & Any adverse event & $\begin{array}{l}\text { Most common were local discomfort and tiredness, which were transient and began within } \\
24 \text { hours after treatment, and were of mild to moderate severity; no serious adverse events } \\
\text { reported }\end{array}$ \\
\hline Skillgate 2007, $n=409$ & $\begin{array}{l}\text { Self-reported events at a } \\
\text { follow-up visit }\end{array}$ & Any adverse event & $\begin{array}{l}\text { Minor short term events limited to muscle soreness, tiredness, and increased pain, most } \\
\text { commonly after first and second treatments; no serious adverse events reported }\end{array}$ \\
\hline $\begin{array}{l}\text { UK BEAM trial } 2004 \\
\mathrm{n}=1334\end{array}$ & $\begin{array}{l}\text { Monitoring by research } \\
\text { team; not elucidated } \\
\text { further }\end{array}$ & $\begin{array}{l}\text { Serious adverse events only, } \\
\text { defined as admission to } \\
\text { hospital or death within one } \\
\text { week of treatment }\end{array}$ & No serious adverse events reported \\
\hline Walker $2013, n=183$ & $\begin{array}{l}\text { Self-reported events at } \\
\text { each follow-up visit }\end{array}$ & Any adverse event & $\begin{array}{l}30 \text { (33\%) of patients in sham group and } 39 \text { ( } 42 \%) \text { in SMT group reported at least } 1 \text { adverse } \\
\text { event; common adverse events were increased pain (sham } 29 \% \text {; SMT } 36 \%) \text {, muscle stiffness } \\
\text { (sham } 29 \% \text {; SMT } 37 \%) \text {, and headache (sham } 17 \% \text {; SMT } 9 \%) \text {. The relative risk was not signif- } \\
\text { icant for adverse event occurrence }(1.24,95 \% \text { confidence interval } 0.85 \text { to } 1.81) \text {, occurrence } \\
\text { of severe adverse events }(1.9,0.98 \text { to } 3.99) \text {, adverse event onset }(0.16,0.02 \text { to } 1.34) \text {, or } \\
\text { duration of adverse events }(1.13,0.59 \text { to } 2.18) \text {; no serious adverse events reported }\end{array}$ \\
\hline Xia $2016, n=192$ & Not reported & Not reported & No serious adverse events reported \\
\hline $\begin{array}{l}\text { Zaproudina 2009, } \\
\mathrm{n}=131\end{array}$ & Not reported & Not reported & $\begin{array}{l}1(2 \%) \text { patient in SMT group and } 2(3 \%) \text { in control group discontinued treatment owing to } \\
\text { worsening of low back pain; no serious adverse events reported }\end{array}$ \\
\hline
\end{tabular}


because these types of studies only weaken rather than strengthen the evidence and should be discouraged. Curiously, this finding contrasts with an earlier study that identified a trend towards better quality studies investigating SMT. ${ }^{77}$ Future studies should focus on identifying moderators likely to influence treatment effects (such as socioeconomic status, level of education), and this is a line of evidence that we are currently pursuing in an individual participant data meta-analysis.

We present average clinical effects for the groups. For a better interpretation of the results, benefit might arise if additional analyses are included in future trials, such as the proportion of patients achieving a clinically meaningful response. This could be obscured by group averages. Additionally, we can better interpret the effects if greater attention is paid to the qualitative components of interventions, such as the context of the visit, and patient beliefs and preferences. ${ }^{78}$

\section{Comparison with other studies}

Ostensibly, these results are consistent with our previous review. ${ }^{19}$ One major difference between the reviews was the classification of the comparator: in the first review we classified therapies into effective and non-effective, whereas in this review we classified them into recommended and non-recommended therapies. It was thought that this would best help the translation of findings to clinical practice. We based the classification of the comparator on recent guidelines, but this was not always clear because evidence among the different guidelines conflicted (eg, acupuncture), or a given therapy was not classified (eg, back school). We examined the impact of classifying these therapies with their opposing comparator in sensitivity analyses (data not shown), and this did not affect our results. Furthermore, our results are consistent with other recently published high quality systematic reviews ${ }^{79-81}$ and guidelines that recommend SMT. ${ }^{235}$

\section{Implications for clinicians}

SMT can be delivered as a standalone therapy, although it is typically offered within the constructs of a broader treatment package, together with exercise therapy or combined with usual care, as is recommended in recent national guidelines for low back pain. ${ }^{52}$ This is important because SMT is by nature a passive treatment. Therefore, to prevent inappropriate behaviour and to empower patients to take control of their condition it is vital that practitioners impart the proper message to their patients.

The incidence of adverse events and serious adverse events based on the studies included here are difficult to assess because less than half of the randomised controlled trials examined these, and in most of the studies the methodology was unclear. Importantly, given the low incidence of serious adverse events, randomised controlled trials are not the design of choice. Based on a recent systematic review, serious adverse events after SMT for low back pain are thought to be rare and include case reports of cauda equina syndrome, fractures, and neurological or vascular compromise. ${ }^{83}$ A recent comprehensive scoping review, which examined the risks of manual treatments to the spine, identified 250 articles in which serious adverse events were reported. Most of these focused on adverse events after treatment to the neck. ${ }^{84}$ The body of evidence, which includes data from large, prospective observational studies of SMT, suggests that benign adverse events are common and serious adverse events are rare. The incidence and causal relations with serious adverse events are difficult to establish, in part due to inherent methodological limitations of the included studies. Importantly, predictors of these events are unclear. Given this, clinicians should ensure that patients are fully informed of potential risks before treatment.

\section{Implications for policy makers and other researchers}

Although we focused on the effects of SMT in this review, the costs associated with care should also be considered. The most recent systematic review on cost effectiveness of non-invasive and non-drug interventions for the treatment of low back pain concluded that manual treatments, including SMT and massage, should be considered a cost effective option. ${ }^{85}$ This conclusion, however, was based on 10 studies, only two of which are included in this review. $^{73} 86$ Another recent systematic review that focused on the effects of SMT for spinal pain concluded that SMT is a cost effective option when used alone or in combination with other treatments. ${ }^{87}$ However, this conclusion was based on six studies, including studies that examined the effect of SMT for the treatment of neck pain, and was limited to the same two studies cited previously. ${ }^{7386}$ To our knowledge, no other economic evaluations have been done of SMT for the treatment of chronic low back pain. Although we did not actively search for these types of evaluations because that was an objective of this review, it is unlikely we missed any economic evaluations in these studies. The primary author knows this literature well and regularly attends meetings in which trial results are presented. Furthermore, it is likely that studies as well as protocols would have referenced an economic evaluation if it existed. Therefore, it remains to be determined whether SMT is a cost effective option for the treatment of chronic low back pain.

\section{Limitations of this study}

The most important limitations are those inherent to most (if not all) systematic reviews-namely, the limited number of studies with a low risk of bias, as well as ambiguity about the impact of publication bias. Furthermore, we could not resolve the problem related to statistical heterogeneity nor is this likely to be resolved in future reviews: studies of SMT are conducted in varied settings, among different populations, using several methods of recruitment and SMT techniques that are subsequently compared with 
various types of therapies. Finally, in most studies it was unclear if the research team was multidisciplinary, and whether it included clinicians involved in the treatment of patients, but perhaps most importantly, given that disclosure was often not reported, potential conflicts of interest cannot be ruled out.

\section{Recommendations for future study}

Future trials of SMT for low back pain should include an economic evaluation; an analysis of the proportion of patients who achieved a specified level of pain relief (eg, percentage of those experiencing 50\% pain improvement); a better description of the qualitative components of SMT, such as the context of the visit, patient beliefs, and preferences, and also quantitative components, such as factors that are likely to influence treatment.

The evidence suggests that SMT results in a modest, average clinical effect at best: future trials on the effect of SMT for chronic low back pain are not necessary, unless they contain a novel approach, are well conducted, and address any of these specific recommendations.

Private or governmental agencies should refrain from funding small trials that are poorly conceived.

\section{Conclusions}

SMT produces similar effects to recommended therapies for chronic low back pain but results in clinically better effects for short term improvement in function compared with non-recommended therapies, sham therapy, or when added as an adjuvant therapy. Clinicians should inform their patients of the potential risks of adverse events associated with SMT.

We thank the editorial board of the Cochrane Back and Neck Review Group for its constructive comments, particularly Shireen Harbin, and those authors who provided clarification of their trials for this update.

Systematic review registration: A protocol of this review is registered with the Cochrane Library. Rubinstein SM, van Middelkoop M, Assendelft WJJ, de Boer M, van Tulder MW. Spinal manipulative therapy for chronic low-back pain. Cochrane Database Syst Rev 2009(4):CD008112; doi:10.1002/14651858.CD008112.

Contributors: SMR, MWvT, and WJJA conceived and designed the study. SMR, AdeZ, MRdeB, and MWVT analysed and interpreted the data. SMR, AdeZ, and MWVT drafted the review. All authors critically revised the article for important intellectual content and gave final approval for the article. MRdeB provided statistical expertise. SMR provided administrative, technical, and logistical support. SMR, AdeZ, and MvM (2011 publication) and MRdeB and WJJA (2004 publication) collected and assembled the data. The corresponding author attests that all listed authors meet authorship criteria and that no others meeting the criteria have been omitted.

Funding: None.

Competing interests: All authors have completed the ICMJE uniform disclosure form at www.icmje.org/coi_disclosure.pdf and declare: SMR received personal grants from the European Chiropractors' Union (ECU), the European Centre for Chiropractic Research Excellence (ECCRE), the Belgian Chiropractic Association (BVC) and the Netherlands Chiropractic Association (NCA) for his position at the Vrije Universiteit Amsterdam. He also received funding for a research project on chiropractic care for the elderly from the European Centre for Chiropractic Research and Excellence (ECCRE). AdeZ received a grant from the European Chiropractors' Union (ECU) (grant No A14.03), for an independent study on the effects of SMT. SMR and AdeZ declare that they work in their own private clinics as chiropractors. The remaining authors received no support from any organisation for the submitted work; have no financial relationships with any organisations that might have an interest in the submitted work in the previous three years; and have no other relationships or activities that could appear to have influenced the submitted work. Ethical approval: Not required.

Data sharing: Details of the characteristics of the included studies are available from the corresponding author at s.m.rubinstein@vu.nl.

Transparency: All authors affirm that the manuscript is an honest, accurate, and transparent account of the study being reported; that no important aspects of the study have been omitted; and that any discrepancies from the study as planned (and, if relevant, registered) have been explained.

This is an Open Access article distributed in accordance with the Creative Commons Attribution Non Commercial (CC BY-NC 4.0) license, which permits others to distribute, remix, adapt, build upon this work non-commercially, and license their derivative works on different terms, provided the original work is properly cited and the use is noncommercial. See: http://creativecommons.org/licenses/by-nc/4.0/.

1 GBD 2016 Disease and Injury Incidence and Prevalence Collaborators. Global, regional, and national incidence, prevalence, and years lived with disability for 328 diseases and injuries for 195 countries, 1990-2016: a systematic analysis for the Global Burden of Disease Study 2016. Lancet 2017;390:1211-59. doi:10.1016/ S0140-6736(17)32154-2

2 Airaksinen O, Brox Jl, Cedraschi C, et al, COST B13 Working Group on Guidelines for Chronic Low Back Pain. Chapter 4. European guidelines for the management of chronic nonspecific low back pain. Eur Spine / 2006;15(Suppl 2):S192-300. doi:10.1007/s00586006-1072-1

3 Qaseem A, Wilt TJ, McLean RM, Forciea MAClinical Guidelines Committee of the American College of Physicians. Noninvasive Treatments for Acute, Subacute, and Chronic Low Back Pain: A Clinical Practice Guideline From the American College of Physicians. Ann Intern Med 2017;166:514-30. doi:10.7326/M16-2367

4 Bons SCS, Borg MAJP, Van den Donk M, et al. NHG guideline for aspecific low-back pain, 2017. www.nhgorg/standaarden/ samenvatting/aspecifieke-lagerugpijn\#idp23613872.

5 NICE guideline. Low back pain and sciatica in over 16s: assessment and management. www.nice.org.uk/guidance/NG59/chapter/ Recommendations\#non-invasive-treatments-for-low-back-pain-andsciatica, 2016

6 Koes BW, van Tulder M, Lin CW, Macedo LG, McAuley J, Maher C. An updated overview of clinical guidelines for the management of nonspecific low back pain in primary care. Eur Spine / 2010;19:2075-94. doi:10.1007/s00586-010-1502-y

7 Foster NE, Anema JR, Cherkin D, et al. Prevention and treatment of low back pain: evidence, challenges, and promising directions. (1474-547X)

8 Sandoz R. The significance of the manipulative crack and of other articular noises. Ann Swiss Chiro Assoc 1969;4:47-68.

9 Bialosky JE, Bishop MD, Robinson ME, Zeppieri GJr, George SZ. Spinal manipulative therapy has an immediate effect on thermal pain sensitivity in people with low back pain: a randomized controlled trial. Phys Ther 2009;89:1292-303. doi:10.2522/ptj.20090058

10 Fryer $\mathrm{G}$. Integrating osteopathic approaches based on biopsychosocial therapeutic mechanisms. Part 1: The mechanisms. Int J Osteopath Med 2017;25:30-41. doi:10.1016/j. ijosm.2017.05.002

11 Wong AYL, Parent EC, Dhillon SS, Prasad N, Kawchuk GN. Do participants with low back pain who respond to spinal manipulative therapy differ biomechanically from nonresponders, untreated controls or asymptomatic controls? Spine (Phila Pa 1976) 2015;40:1329-37. doi:10.1097/BRS.0000000000000981

12 Xia T, Long CR, Vining RD, et al. Association of lumbar spine stiffness and flexion-relaxation phenomenon with patient-reported outcomes in adults with chronic low back pain - a single-arm clinical trial investigating the effects of thrust spinal manipulation. BMC Complement Altern Med 2017;17:303. doi:10.1186/s12906-0171821-1

13 Bialosky JE, Bishop MD, Price DD, Robinson ME, George SZ. The mechanisms of manual therapy in the treatment of musculoskeletal pain: a comprehensive model. Man Ther 2009;14:531-8. doi:10.1016/j.math.2008.09.001

14 Bialosky JE, George SZ, Horn ME, Price DD, Staud R, Robinson ME. Spinal manipulative therapy-specific changes in pain sensitivity in individuals with low back pain (NCT01168999). J Pain 2014;15:136-48. doi:10.1016/j.jpain.2013.10.005

15 Coronado RA, Gay CW, Bialosky JE, Carnaby GD, Bishop MD, George SZ. Changes in pain sensitivity following spinal manipulation: a systematic review and meta-analysis. J Electromyogr Kinesiol 2012;22:752-67. doi:10.1016/j.jelekin.2011.12.013

16 Currie SJ, Myers CA, Durso C, Enebo BA, Davidson BS. The neuromuscular response to spinal manipulation in the presence of 
pain. J Manipulative Physiol Ther 2016;39:288-93. doi:10.1016/j. impt.2016.02.011

17 Dorron SL, Losco BE, Drummond PD, Walker BF. Effect of lumbar spinal manipulation on local and remote pressure pain threshold and pinprick sensitivity in asymptomatic individuals: a randomised trial. Chiropr Man Therap 2016;24:47-56. doi:10.1186/s12998-0160128-5

18 Randoll C, Gagnon-Normandin V, Tessier J, et al. The mechanism of back pain relief by spinal manipulation relies on decreased temporal summation of pain. Neuroscience 2017;349:220-8. doi:10.1016/j. neuroscience.2017.03.006

19 Rubinstein SM, van Middelkoop M, Assendelft WJJ, de Boer MR, van Tulder MW. Spinal manipulative therapy for chronic low-back pain. Cochrane Database Syst Rev 2011;(2):CD008112.

20 Rubinstein SM, van Middelkoop M, Assendelft WJJ, de Boer MR, van Tulder MW. Spinal manipulative therapy for chronic low-back pain. Cochrane Database Syst Rev 2011;(2):CD008112.

21 Higgins JPT. Green S. Cochrane Handbook for Systematic Reviews of Interventions. The Cochrane Collaboration, 2011; Version 5.1.0 [updated March 2011]

22 DerSimonian R, Laird N. Meta-analysis in clinical trials. Control Clin Trials 1986:7:177-88. doi:10.1016/0197-2456(86)90046-2

23 IntHout J, loannidis JPA, Rovers MM, et al. Plea for routinely presenting prediction intervals in meta-analysis. $B M$ J Open 2016;6:e010247. doi:10.1136/bmjopen-e47

24 Cohen J. Statistical Power Analysis for the Behavioral Sciences. Academic Press, 1988: 1-474.

25 Furlan AD, Pennick V, Bombardier C, van Tulder MEditorial Board, Cochrane Back Review Group. 2009 updated method guidelines for systematic reviews in the Cochrane Back Review Group. Spine (Phila Pa 1976) 2009;34:1929-41. doi:10.1097/ BRS.0b013e3181b1c99f

26 Savovic J, Turner RM, Mawdsley D, et al. Association Between Risk-of-Bias Assessments and Results of Randomized Trials in Cochrane Reviews: the ROBES Meta-Epidemiologic Study. Am J Epidemiol 2018;187;1113-22. doi:10.1093/aje/kw×344

27 Balthazard P, de Goumoens P, Rivier G, Demeulenaere P, Ballabeni P, Dériaz $O$. Manual therapy followed by specific active exercises versus a placebo followed by specific active exercises on the improvement of functional disability in patients with chronic non specific low back pain: a randomized controlled trial. BMC Musculoskelet Disord 2012;13:162. doi:10.1186/1471-2474-13-162

28 Brønfort G, Goldsmith CH, Nelson CF, Boline PD, Anderson AV. Trunk exercise combined with spinal manipulative or NSAID therapy for chronic low back pain: a randomized, observer-blinded clinical trial. Manipulative Physiol Ther 1996;19:570-82.

29 Bronfort G, Maiers MJ, Evans RL, et al. Supervised exercise, spinal manipulation, and home exercise for chronic low back pain: a randomized clinical trial. Spine J 2011;11:585-98. doi:10.1016/j. spinee.2011.01.036

30 Castro-Sánchez AM, Lara-Palomo IC, Matarán-Peñarrocha GA, et al. Short-term effectiveness of spinal manipulative therapy versus functional technique in patients with chronic nonspecific low back pain: a pragmatic randomized controlled trial. Spine J 2016;16:30212. doi:10.1016/j.spinee.2015.08.057

31 Cecchi F, Molino-Lova R, Chiti M, et al. Spinal manipulation compared with back school and with individually delivered physiotherapy for the treatment of chronic low back pain: a randomized trial with one-year follow-up. Clin Rehabil 2010;24:26-36. doi:10.1177/0269215509342328

32 Chown M, Whittamore L, Rush M, et al. A prospective study of patients with chronic back pain randomised to group exercise, physiotherapy or osteopathy. Physiotherapy 2008;94:21-8. doi:10.1016/j.physio.2007.04.014

33 Cook C, Learman K, Showalter C, Kabbaz V, O’Halloran B. Early use of thrust manipulation versus non-thrust manipulation: a randomized clinical trial. Man Ther 2013;18:191-8. doi:10.1016/j. math.2012.08.005

34 Dougherty PE, Karuza J, Savino D, Katz P. Evaluation of a modified clinical prediction rule for use with spinal manipulative therapy in patients with chronic low back pain: a randomized clinical trial. Chiropr Man Therap 2014;22:41. doi:10.1186/s12998-014-0041. 8

35 Evans DP, Burke MS, Lloyd KN, Roberts EE, Roberts GM. Lumbar spinal manipulation on trial. Part I--clinical assessment. Rheumatol Rehabil 1978:17:46-53. doi:10.1093/rheumatology/17.1.46

36 Ferreira ML, Ferreira PH, Latimer J, et al. Comparison of general exercise, motor control exercise and spinal manipulative therapy for chronic low back pain: A randomized trial. Pain 2007;131:31-7. doi:10.1016/j.pain.2006.12.008

37 Ghroubi S, Elleuch H, Baklouti S, Elleuch MH. [Chronic low back pain and vertebral manipulation][French]. Ann Readapt Med Phys 2007:50:570-6. doi:10.1016/i.annrmp.2007.02.012

38 Gibson T, Grahame R, Harkness J, Woo P, Blagrave P, Hills R. Controlled comparison of short-wave diathermy treatment with osteopathic treatment in non-specific low back pain. Lancet 1985;1:1258-61. doi:10.1016/S0140-6736(85)92323-2

39 Goldby LJ, Moore AP, Doust J, Trew ME. A randomized controlled trial investigating the efficiency of musculoskeletal physiotherapy on chronic low back disorder. Spine (Phila Pa 1976) 2006;31:1083-93. doi:10.1097/01.brs.0000216464.37504.64

40 Gudavalli MR, Cambron JA, McGregor M, et al. A randomized clinical trial and subgroup analysis to compare flexion-distraction with active exercise for chronic low back pain. Eur Spine / 2006;15:1070-82. doi:10.1007/s00586-005-0021-8

41 Haas M, Vavrek D, Peterson D, Polissar N, Neradilek MB. Doseresponse and efficacy of spinal manipulation for care of chronic low back pain: a randomized controlled trial. Spine / 2014;14:1106 16. doi:10.1016/j.spinee.2013.07.468

42 Hemmilä HM, Keinänen-Kiukaanniemi SM, Levoska S, Puska P. Long-term effectiveness of bone-setting, light exercise therapy, and physiotherapy for prolonged back pain: a randomized controlled trial. J Manipulative Physiol Ther 2002;25:99-104. doi:10.1067/ mmt.2002.122329

43 Hidalgo B, Pitance L, Hall T, Detrembleur C, Nielens H. Short-term effects of Mulligan mobilization with movement on pain, disability, and kinematic spinal movements in patients with nonspecific low back pain: a randomized placebo-controlled trial. / Manipulative Physiol Ther 2015;38:365-74.

44 Hondras MA, Long CR, Cao Y, Rowell RM, Meeker WC. A randomized controlled trial comparing 2 types of spinal manipulation and minimal conservative medical care for adults 55 years and older with subacute or chronic low back pain. J Manipulative Physiol Ther 2009;32:330-43. doi:10.1016/j.jmpt.2009.04.012

45 Hsieh CY, Adams AH, Tobis J, et al. Effectiveness of four conservative treatments for subacute low back pain: a randomized clinical trial. Spine (Phila Pa 1976) 2002;27:1142-8. doi:10.1097/00007632200206010-00003

46 Hurwitz EL, Morgenstern H, Harber P, et al, University of California-Los Angeles. A randomized trial of medical care with and without physical therapy and chiropractic care with and without physical modalities for patients with low back pain: 6-month follow-up outcomes from the UCLA low back pain study. Spine (Phila Pa 1976) 2002;27:2193204. doi:10.1097/00007632-200210150-00002

47 Koes BW, Bouter LM, van Mameren $\mathrm{H}$, et al. The effectiveness of manual therapy, physiotherapy, and treatment by the general practitioner for nonspecific back and neck complaints. A randomized clinical trial. Spine (Phila Pa 1976) 1992;17:28-35. doi:10.1097/00007632-199201000-00005

48 Krekoukias G, Gelalis ID, Xenakis T, Gioftsos G, Dimitriadis Z, Sakellari V. Spinal mobilization vs conventional physiotherapy in the management of chronic low back pain due to spinal disk degeneration: a randomized controlled trial. J Man Manip Ther 2017;25:66-73. doi:10.1080/10669817.2016.1184435

49 Licciardone JC, Stoll ST, Fulda KG, et al. Osteopathic manipulative treatment for chronic low back pain: a randomized controlled trial. Spine (Phila Pa 1976) 2003;28:1355-62. doi:10.1097/01. BRS.0000067110.61471.7D

50 Mohseni-Bandpei MA, Critchley J, Staunton T, et al. A prospective randomised controlled trial of spinal manipulation and ultrasound in the treatment of chronic low back pain. Physiotherapy 2006;92:3442. doi:10.1016/j.physio.2005.05.005

51 Muller R, Giles LG. Long-term follow-up of a randomized clinical trial assessing the efficacy of medication, acupuncture, and spinal manipulation for chronic mechanical spinal pain syndromes. J Manipulative Physiol Ther 2005;28:3-11. doi:10.1016/j. jmpt.2004.12.004

52 Paatelma M, Kilpikoski S, Simonen R, Heinonen A, Alen M, Videman T. Orthopaedic manual therapy, McKenzie method or advice only for low back pain in working adults: a randomized controlled trial with one year follow-up. J Rehabil Med 2008;40:858-63. doi:10.2340/16501977-0262

53 Petersen T, Larsen K, Nordsteen J, Olsen S, Fournier G, Jacobsen $\mathrm{S}$. The McKenzie method compared with manipulation when used adjunctive to information and advice in low back pain patients presenting with centralization or peripheralization: a randomized controlled trial. Spine (Phila Pa 1976) 2011;36:1999-2010. doi:10.1097/BRS.0b013e318201ee8e

54 Pope MH, Phillips RB, Haugh LD, Hsieh CY, MacDonald L, Haldeman S. A prospective randomized three-week trial of spinal manipulation, transcutaneous muscle stimulation, massage and corset in the treatment of subacute low back pain. Spine (Phila Po 1976) 1994;19:2571-7. doi:10.1097/00007632-19941100100013

55 Postacchini F, Facchini M, Palieri P. Efficacy of various forms of conservative treatment in low back pain: a comparative study. NeuroOrthopedics 1988;6:28-35.

56 Rasmussen J, Laetgaard J, Lindecrona AL, Qvistgaard E, Bliddal H. Manipulation does not add to the effect of extension exercises in chronic low-back pain (LBP). A randomized, controlled, double 
blind study. Joint Bone Spine 2008;75:708-13. doi:10.1016/j. jbspin.2007.12.011

57 Rasmussen-Barr E, Nilsson-Wikmar L, Arvidsson I. Stabilizing training compared with manual treatment in sub-acute and chronic low-back pain. Man Ther 2003;8:233-41. doi:10.1016/S1356 689X(03)00053-5

58 Samir SM, Zak YLA, Soliman MO. Mulligan versus Maitland mobilizations in patients with chronic low back dysfunction. Int Pharm Tech Res 2016;9:92-9.

59 Sarker KK, Mohanty U, Sethi J. Effect of spinal manipulation on postural instability in patients with non specific low back pain. Int) Pharm Bio Sci 2017;7:992-9.

60 Senna MK, Machaly SA. Does maintained spinal manipulation therapy for chronic nonspecific low back pain result in better long-term outcome?Spine (Phila Pa 1976) 2011;36:1427-37. doi:10.1097/ BRS.0b013e3181f5 dfeo

61 Skillgate E, Vingård E, Alfredsson L. Naprapathic manual therapy or evidence-based care for back and neck pain: a randomized, controlled trial. Clin J Pain 2007;23:431-9. doi:10.1097/ AJP.0b013e31805593d8

62 UK BEAM Trial Team. United Kingdom back pain exercise and manipulation (UK BEAM) randomised trial: effectiveness of physical treatments for back pain in primary care. BMJ 2004;329:1377-81. doi:10.1136/bmj.38282.669225.AE

63 Ulger O, Demirel A, Oz M, Tamer S. The effect of manual therapy and exercise in patients with chronic low back pain: Double blind randomized controlled trial. J Back Musculoskelet Rehabil 2017;30:1303-9. doi:10.3233/BMR-169673

64 Verma Y, Goyal M. Narkeesh. Pain, range of motion and back strength in chronic mechanical low back pain before \& after lumbar mobilisation. Int J Physiother Res 2013;3:48-57

65 Vismara L, Cimolin V, Menegoni F, et al. Osteopathic manipulative treatment in obese patients with chronic low back pain: a pilot study. Man Ther 2012;17:451-5. doi:10.1016/j.math.2012.05.002

66 Waagen GN, Haldeman S, Cook G, et al. Short term trial of chiropractic adjustments for the relief of chronic low back pain. Man Med 1986;2:63-7.

67 Walker BF, Hebert JJ, Stomski NJ, Losco B, French SD. Short-term usual chiropractic care for spinal pain: a randomized controlled trial. Spine (Phila Pa 1976) 2013;38:2071-8. doi:10.1097/01. brs.0000435032.73187.c7

68 Waqqar S, Shakil-Ur-Rehman S, Ahmad S. McKenzie treatment versus mulligan sustained natural apophyseal glides for chronic mechanical low back pain. PakJ Med Sci 2016;32:476-9.

69 Wilkey A, Gregory M, Byfield D, McCarthy PW. A comparison between chiropractic management and pain clinic management for chronic low-back pain in a national health service outpatient clinic. J Altern Complement Med 2008;14:465-73. doi:10.1089/acm.2007.0796

70 Xia T, Long CR, Gudavalli MR, et al. Similar Effects of Thrust and Nonthrust Spinal Manipulation Found in Adults With Subacute and Chronic Low Back Pain: A Controlled Trial With Adaptive Allocation. Spine (Phila Pa 1976) 2016;41:E702-9. doi:10.1097/ BRS.0000000000001373

71 Zaproudina N, Hietikko T, Hänninen OOP, Airaksinen O. Effectiveness of traditional bone setting in treating chronic low back pain: a randomised pilot trial. Complement Ther Med 2009;17:23-8. doi:10.1016/j.ctim.2008.08.005

72 Licciardone JC, Minotti DE, Gatchel RJ, Kearns CM, Singh KP. Osteopathic manual treatment and ultrasound therapy for chronic low back pain: a randomized controlled trial. Ann Fam Med 2013;11:122-9. doi:10.1370/afm.1468

73 UK BEAM Trial Team. United Kingdom back pain exercise and manipulation (UK BEAM) randomised trial: cost effectiveness of physical treatments for back pain in primary care. BMJ 2004;329:1381-5. doi:10.1136/bmj.38282.607859.AE

74 Gilbert JR, Taylor DW, Hildebrand A, Evans C. Clinical trial of common treatments for low back pain in family practice. BMJ 1985;291:7914. doi:10.1136/bmj.291.6498.791

75 Hurwitz EL, Morgenstern H, Kominski GF, Yu F, Chiang LM. A randomized trial of chiropractic and medical care for patients with low back pain: eighteen-month follow-up outcomes from the UCLA low back pain study. Spine (Phila Pa 1976) 2006;31:611-21, discussion 622. doi:10.1097/01.brs.0000202559.41193.b2

76 Walker BF, Hebert JJ, Stomski NJ, et al. Outcomes of usual chiropractic. The OUCH randomized controlled trial of adverse events. Spine (Phila Pa 1976) 2013;38:1723-9. doi:10.1097/BRS.0b013e31829fefe4

77 Rubinstein SM, van Eekelen R, Oosterhuis T, de Boer MR, Ostelo RW, van Tulder MW. The risk of bias and sample size of trials of spinal manipulative therapy for low back and neck pain: analysis and recommendations. J Manipulative Physiol Ther 2014;37:523-41. doi:10.1016/j.jmpt.2014.07.007

78 Dima A, Lewith GT, Little P, Moss-Morris R, Foster NE, Bishop FL. Identifying patients' beliefs about treatments for chronic low back pain in primary care: a focus group study. $\mathrm{Br} / \mathrm{Gen}$ Pract 2013;63:e490-8. doi:10.3399/bjgp13X669211

79 Chou R, Deyo R, Friedly J, et al. Noninvasive Treatments for Low Back Pain. Rockville (MD): Agency for Healthcare Research and Quality (US); 2016 Feb Report No: 16-EHC004-EF AHRQ Comparative Effectiveness Reviews 2016; Report No: 16-ReporEHC004-EF.

80 Franke H, Franke JD, Fryer G. Osteopathic manipulative treatment for nonspecific low back pain: a systematic review and meta-analysis. BMC Musculoskelet Disord 2014;15:286. doi:10.1186/1471-2474$15-286$

81 Ruddock JK, Sallis H, Ness A, Perry RE. Spinal Manipulation Vs Sham Manipulation for Nonspecific Low Back Pain: A Systematic Review and Meta-analysis. J Chiropr Med 2016;15:165-83. doi:10.1016/j. jcm.2016.04.014

82 Stochkendahl MJ, Kjaer P, Hartvigsen J, et al. National Clinical Guidelines for non-surgical treatment of patients with recent onset low back pain or lumbar radiculopathy. Eur Spine J 2018;27:60-75. doi:10.1007/s00586-017-5099-2

83 Hebert JJ, Stomski NJ, French SD, Rubinstein SM. Serious Adverse Events and Spinal Manipulative Therapy of the Low Back Region: A Systematic Review of Cases. J Manipulative Physiol Ther 2015;38:677-91. doi:10.1016/j.jmpt.2013.05.009

84 Swait G, Finch R. What are the risks of manual treatment of the spine? A scoping review for clinicians. Chiropr Man Therap 2017;25:37. doi:10.1186/s12998-017-0168-5

85 Andronis L, Kinghorn P, Qiao S, Whitehurst DG, Durrell S, McLeod H. Cost-Effectiveness of Non-Invasive and Non-Pharmacological Interventions for Low Back Pain: a Systematic Literature Review. Appl Health Econ Health Policy 2017;15:173-201. doi:10.1007/s40258 016-0268-8

86 Niemistö L, Rissanen P, Sarna S, Lahtinen-Suopanki T, Lindgren $\mathrm{KA}$, Hurri H. Cost-effectiveness of combined manipulation, stabilizing exercises, and physician consultation compared to physician consultation alone for chronic low back pain: a prospective randomized trial with 2-year follow-up. Spine (Phila Pa 1976) 2005;30:1109-15. doi:10.1097/01. brs.0000162569.00685.7b

87 Michaleff ZA, Lin CW, Maher CG, van Tulder MW. Spinal manipulation epidemiology: systematic review of cost effectiveness studies. Electromyogr Kinesiol 2012;22:655-62. doi:10.1016/j. jelekin.2012.02.011

Supplementary file: additional information 